\title{
Counting Blue(tooth) Cars: Assessing Cellphone Use AMong Vehicle Drivers in THE MIDWESTERN USA
}

\author{
Daniel J. Kruger'1, Micheale Falbo'1, Camille Gazoul', Ethan Cole', Noreen Nader'1, \\ Sophie Blanchard', Ailiya Duan' ${ }^{2}$, Shannon Murphy1, Dora Juhasz ${ }^{2}$, Claire \\ Saunders ${ }^{2}$, Peter Sonnega ${ }^{2}$, Jessica Kruger ${ }^{3}$, Jon Elhai ${ }^{4}$
}

1Population Studies Center, University of Michigan, Ann Arbor, MI, USA

${ }^{2}$ Literature, Science and Arts, University of Michigan, Ann Arbor, MI, USA

${ }^{3}$ Department of Community Health and Health Behavior, SUNY at Buffalo, New York, USA

${ }^{4}$ Department of Psychology and Psychiatry, University of Toledo College of Literature, Languages and Social Sciences, Toledo, OH, USA

kruger@umich.edu

\begin{abstract}
Mobile cell phones are integral to social fabric of the contemporary United States and other technologically advanced societies. There is considerable research on the psychology and behavior of cell phone use, though most of the scientific literature is based on survey studies and experience sampling applications. Cell phone use while driving increases the risk of automobile accidents. Survey responses regarding controversial and illegal behaviors are often biased by socially-desirable responding. Precise data on population usage patterns are typically proprietary. Naturalistic observations may provide unique information that complements findings from self-report survey methods and address research questions outside the proper scope of surveys and topics on which socially-desirably responding may occur. We examined cell phone use among drivers $(N=2538)$ in a Midwestern USA college town. In the study setting, texting while driving is illegal, whereas both hands-free (e.g., Bluetooth-enabled) and phone-inhand calls are permitted. However, drivers cited for traffic violations may also be charged with careless driving due to cell phone use. Overall, 23\% of drivers were observed using their phones; 9\% were talking with their phones in hand, 9\% were texting, and 6.4\% of those with no passengers in the car were observed talking (likely on a hands-free, or Bluetooth, call). Older drivers were less likely to be texting. Drivers were less likely to be using their phones when they had passengers and when it was raining. We demonstrate the value of observational studies for understanding technology use; our results complement those of self-report survey research.
\end{abstract}

Keywords: Cellphone, automobile, driving, hands-free, texting. 


\section{INTRODUCTION}

Mobile cell phone use is quickly becoming ubiquitous in industrialized countries. Polling indicates that $77 \%$ of all U.S. adults own a smartphone, and $92 \%$ of those aged 18 to 29 own a smartphone (Pew Research Center, 2017). There is considerable research on psychology and behavior related to cell phone use, though most of the literature is based on survey studies and experience sampling applications (for reviews, see: Elhai et al., 2017; Rosen, Whaling, Carrier, Cheever, \& Rokkum, 2013). For example, college students in the Midwestern USA reported using cell phones an average of 290 minutes (nearly five hours) per day (Lepp, Li, Barkley, \& Salehi-Esfahani, 2015). The addictiveness of cell phones for undergraduates is driven by desires to connect socially (Roberts, Yaya, \& Manolis, 2014). Those who experience greater psychological dependency on cell phones are more likely to have signal-detection errors, where they perceive ringing, vibrations, and/or other notifications associated with cell phone calls or messages when no message actually registers on the phone (Kruger \& Djerf, 2017). These phantom signals are more prevalent among those higher in attachment anxiety, who worry that their relationship partners do not share feelings of affiliation and worry about being abandoned (Kruger \& Djerf, 2015).

Cell phone usage in the presence of social companions can interfere with live relationships. The use of cell phones is generally thought to interfere with live conversations (Rainie \& Zickuhr, 2015). Even young adults, who have higher rates of cell phone usage than older adults (Demirci et al., 2015; van Deursen et al., 2015), consider this behavior inappropriate (Forgays, Hyman, \& Schreiber, 2014). The attention that is diverted from one's companion and towards one's cell phone can adversely affect relationship satisfaction (Roberts \& David, 2016). The studies reviewed above highlight the social aspects of cell phone usage and the interference between one's virtual and nonvirtual social worlds.

The accuracy of self-reported cell phone usage has been called into question as it only moderately correlates with objective server log data (Boase \& Ling, 2013; Elhai et al., in press). Precise data on population usage patterns are typically proprietary and do not include social or environmental context. Naturalistic observations may provide unique information that complements findings from self-report survey methods and address research questions outside the proper scope of surveys. Naturalistic observational studies of cell phone use (e.g. Finkel \& Kruger, 2012; Kruger et al., 2017) are rare in comparison to survey methods, however this approach has a history of application in social cognition (Festinger, Riecken, \& Schachter, 1956), ethnography (Geertz, 1973), and consumer marketing research (van Kleef, van Trijpa, \& Luning, 2005). This observational study examined cell phone use by drivers of motor vehicles in the campus and downtown areas of a Midwestern college town.

\section{Driving distraction from cell phone use}

Distraction from phones while driving is a major public safety concern (Terry \& Terry, 2016). Distractions occur in several forms, including physical distractions of using one or both hands to operate a phone, visual distractions of gaze to a phone, auditory distractions from the phone conversation or sounds made by the phone, and cognitive 
distractions from multitasking (Lipovac et al., 2017). Participants in a driving simulator made more serious driving errors when using a cell phone than when not using a cell phone (Sanbonmatsu et al., 2016). Cell phone using participants did not remember making a greater number of serious errors and were less accurate in their estimates of their error rates than non-cell phone using participants (Sanbonmatsu et al., 2016). Driving simulations indicate that using a phone while driving produces reaction time delays equivalent to having the legal limit of alcohol intoxication in most US states (Strayer et al., 2006).

Naturalistic driving data collected by onboard devices indicate that the causes of accidents have dramatically shifted in importance in recent years, driver-related factors (such as impairment, fatigue, and distraction) are now represented in nearly $90 \%$ of crashes (Dingus et al., 2016). Non-driver factors such as vehicle failures and roadway design or condition are declining in importance (Dingus et al., 2016). Among adult drivers involved in a crash interviewed in emergency departments, drivers using mobile phones up to 10 minutes before a crash were four times more likely to be involved in a crash (McEvoy et al., 2005). In a large sample (>223K) of road accidents in the USA, fatalities were nine times more likely when drivers were using mobile phones (Violanti, 1999).

Some municipalities have banned the use of hand-held mobile phones while driving, yet permit "hands-free" (Bluetooth enabled) mobile phone use while driving (Lipovac et al., 2017). Those making a hands-free cell phone call had equivalent reaction time delays to those making a hand-held cell phone call in driving simulations (Strayer et al., 2006). In both studies using a driving simulator and actual driving in a car with on-board monitoring equipment, drivers using cellphones had more mistakes, traffic violations, and accidents, whether they were holding the phone or using a hands-free device (Strayer et al., 2013). Among the emergency department patients, crash risk was the same for hands-free calls as phone in hand calls (McEvoy et al., 2005). A review of current literature suggests that hands-free technology does not increase the safety of mobile phone use while driving (Lipovac et al., 2017).

\section{Current Study}

As noted, there are concerns regarding the accuracy of self-reported cell phone usage. Accuracy of self-reports is a particular concern when investigating behaviors that may be socially undesirable or illegal. Naturalistic observations of behavior are valuable for investigating such behaviors. The current study examines cell phone use by drivers of motor vehicles in the downtown area of a Midwestern college town. Our general research questions were: What proportion of individuals are using phones; what contextual factors influence use of phones? We predicted that younger adults would be more likely to drive while using their phones, especially for texting $(\mathrm{H} 1)$. Text messages are the most frequent method of virtual communication among young adults (Pew Research Center, 2015). Although college students consider texting to be similar in risk to alcohol intoxication while driving, they are more likely to text and believe that their peers have even more favorable beliefs regarding texting while driving than their own (Terry \& Terry, 2016). Older adults were more likely to consider mobile phone use while driving an unsafe activity than younger adults (Hallet, Lambert, \& Regan 2011) and younger 
adults engage in more excessive smartphone use than older adults (Demirci et al., 2015; van Deursen et al., 2015). We predicted that female drivers would have higher rates of phone use than male drivers ( $\mathrm{H} 2)$, based on previous observations (Finkel \& Kruger, 2012; Kruger et al., 2017) and self-reports of phone use rates (e.g., Jeong et al., 2016; Wang et al., 2015). We predicted "interference" of cell phone use with live conversations, in that drivers with passengers would be less likely to use their phones ( $\mathrm{H} 3)$. We predicted that drivers would be less likely to use phones during poor weather conditions (H4; i.e., rain), as these conditions increase the difficulty of driving and may increase the perception of risk from phone use and/or the cognitive load of multitasking.

\section{METHODS}

The research team conducted 38 observational sessions, which varied by location and time of day in March and April and from September through November 2016. Observational sessions took place in the downtown area of a small city in Michigan, USA. Locations which typically have large amounts of slow-moving traffic were selected, $65 \%$ of observations were near a stop sign and $35 \%$ were near a stop light. Combining locations on the same block into observation sites, there were six observation sites overall. All observations were conducted during daylight hours: $25 \%$ of observations (drivers observed) were between 10:00 AM and 12:00 PM, 26\% of observations were between 12:00 PM and 2:00 PM, 24\% of observations were between 2:00 PM and 4:00 $\mathrm{PM}$, and 25\% of observations were between 4:00 PM and 7:00 PM. Observers remained at an observation perch, taking note of their location and the duration of their observational session. Session times ranged from 20 minutes to 150 minutes.

Observers recorded the drivers' sex and approximate age (18-24 or 25 and older), as well as the number of passengers in the vehicle, the weather, and whether or not the driver is texting, talking on the phone with the phone in hand, or talking on the phone hands-free (Bluetooth call use). Observers were instructed to categorize individuals as 25 and older if they appeared noticeably older than a typical undergraduate student. Observations were only recorded when this information could be determined. Each driver was recorded once by one observer. Observers reported that no one noticed them recording behaviors. Observers were not informed of the specific predictions in the hypotheses until data collection was complete.

We conducted a forward stepwise conditional binary logistic regression predicting whether or not drivers were observed using phones, with age, sex, passenger status, and rain status as potential predictors. Pairwise group comparisons were conducted for types of phone use; texting, talking on the phone with the phone in hand, or talking on the phone hands-free. Analyses included only cases with complete data for hypothesis testing. In post-hoc analyses, time of observations were recoded as minutes elapsed in the day $(600-1130)$ and study variables were examined by observation timing.

\section{RESULTS}

In total, 2542 vehicle drivers were observed and 2538 cases had complete data for testing a priori hypotheses. Overall, $23 \%$ of drivers were observed using their phones; $9 \%$ were 
talking with their phones in hand, $9 \%$ were texting or otherwise entering information on their phones, and $6.4 \%$ with no passengers in the car were likely on a hands-free call (observed talking). Age group, passenger status, and rain status entered as significant unique predictors of phone use (see Table 1). Younger drivers were more likely to be observed using phones than older drivers, supporting H2 (see Figure 1). This effect was driven by differences in the likelihood of texting, there were no age differences in handheld phone use or hands-free (Bluetooth) call use. There was no sex difference in observed cell phone use, disconfirming H2. Drivers with passengers were less likely to use their phones for both talking with their in hand and texting, supporting H3 (see Figure 2). Drivers were less likely to be observed in any type of phone use when it was raining, supporting $\mathrm{H} 4$ (see Figure 3). There was a small tendency for phone use to be observed earlier in the day, $\mathrm{r}(2543)=-.045, \mathrm{p}=.023$. It was more likely to be raining earlier in the day, $\mathrm{r}(2543)=-.218, \mathrm{p}<.001$, however the relationship between phone use and rain status remained significant for all types of phone use when controlling for minutes elapsed in the day. There was a small tendency for younger drivers to be observed earlier in the day, $\mathrm{r}(2543)=-.050, \mathrm{p}=.011$, however the relationship between texting and age remained significant when controlling for minutes elapsed in the day. Observation timing was not related to driver sex or passenger presence. There were no significant differences for any type of phone use by whether drivers were observed near a stop sign or a stop light. There were no significant differences between observation sites on the likelihood of observing texting or Bluetooth calls, drivers were significantly more likely to be observed talking with a phone in hand at one site in a university area commercial district than at the site in the downtown commercial district five blocks from the university.

Table 1: Predictors of Observed Cell Phone Use $(\mathrm{N}=2538)$

\begin{tabular}{|c|c|c|c|c|c|}
\hline Tactic & B & SE & Wald & $d f$ & $p$ \\
\hline (Constant?) & -.98 & .07 & 224.45 & 1 & .001 \\
\hline Younger & .20 & .10 & 4.14 & 1 & .042 \\
\hline Passengers? & -.80 & .12 & 46.39 & 1 & .001 \\
\hline Rain? & -1.07 & .22 & 22.94 & 1 & .001 \\
\hline
\end{tabular}

Note: For all variables, $1=$ yes; $0=$ no. 


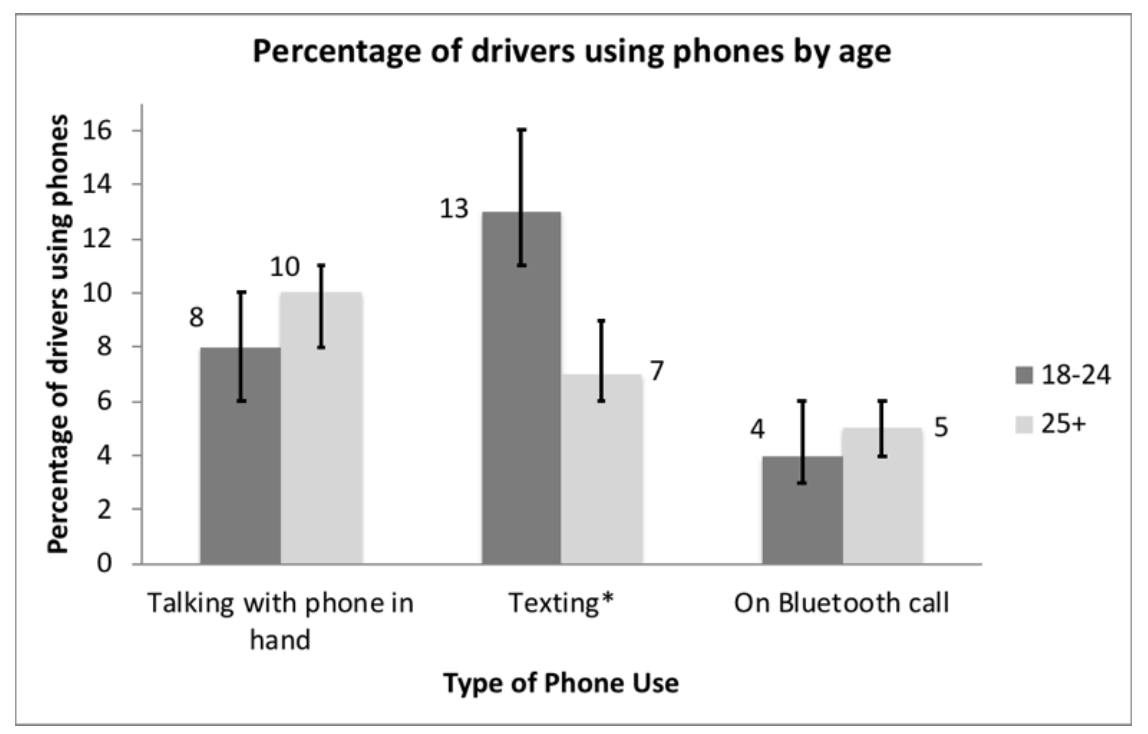

Figure 1: Percentage of drivers on phones by age group with 95\% Confidence Intervals Note: ${ }^{*}$ indicates significant differences between groups.

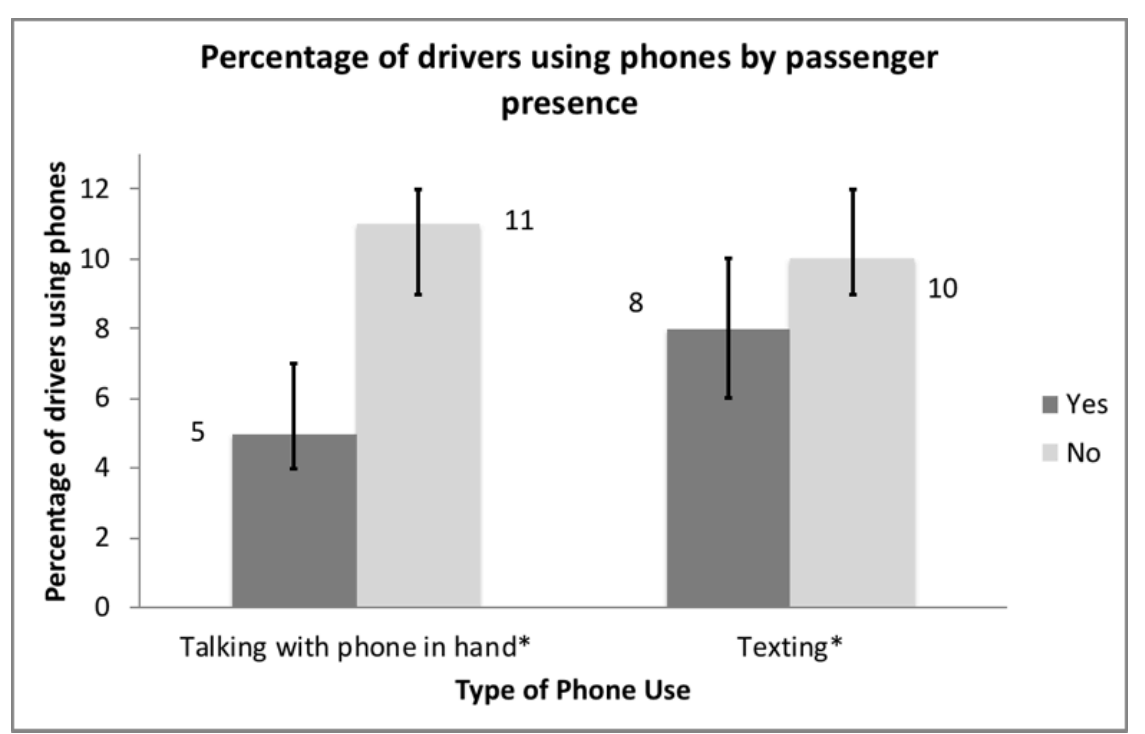

Figure 2: Percentage of of drivers on phones by passenger presence with $95 \%$ Confidence Intervals

Note: ${ }^{*}$ indicates significant differences between groups. 


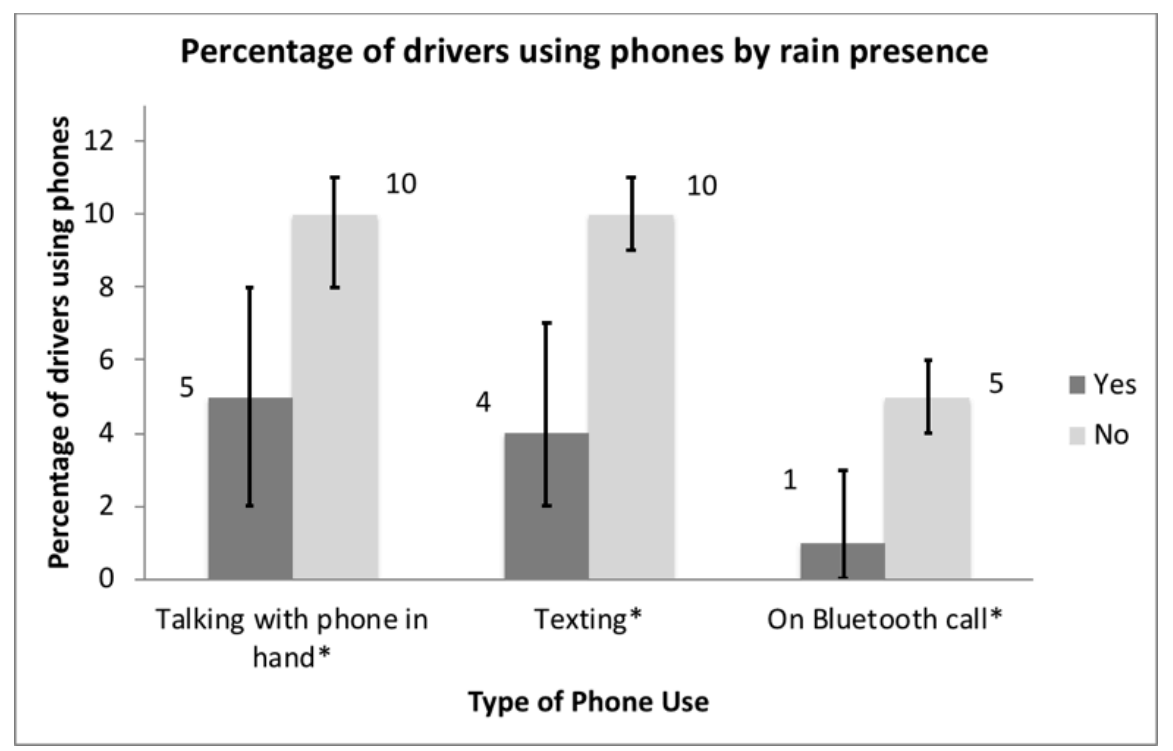

Figure 3: Percentage of drivers on phones by rain presence with $95 \%$ Confidence Intervals.

Note: ${ }^{*}$ indicates significant differences between groups.

\section{DISCUSSION}

Overall, $23 \%$ of drivers were using their phones in some capacity. The high rate of cellphone use is remarkable, given that cellphone use while driving is thought to increase the risk of accidents as much as having the legal limit of alcohol intoxication (Strayer et al., 2006). Although texting while driving has been banned in the state since $2010,9 \%$ of drivers were observed texting or otherwise manually entering information on their phones. Younger drivers had relatively higher rates of phone use for texting, despite the prohibition taking effect before they were licensed or early in their driving history. Motorists are fined $\$ 100$ for their first texting offense, and $\$ 200$ for subsequent offenses. The state does not have a law specifically prohibiting other types of cell phone while driving a vehicle, except for novice drivers. However, a driver distracted by cell phone use who commits a traffic violation could be charged with careless driving, in addition to the specific violation.

Some municipalities have banned the use of hand-held mobile phones while driving, based on the mistaken belief that "hands-free" mobile phone use is safer than hands-on phone use while driving (Lipovac et al., 2017). Driving simulation research indicates that even those who use Bluetooth enabled "hands-free" calls will also use their hands to open applications, dial numbers, and perform other phone related tasks (Strayer et al., 2013). In the current study, drivers without passengers were more likely to be observed talking with phone in hand than on a hands-free call. Although we may underestimate Bluetooth call rates more so than phone-in-hand behaviors (see below), this result suggests that most phone using drivers do not believe that hands-free calls are sufficiently safer to justify their use. 
There was no sex difference observed in rates of phone use, in contrast to results from previous self-report (e.g., Jeong et al., 2016; Wang et al., 2015) and observational studies (Finkel \& Kruger, 2012; Kruger et al., 2017) of general phone use. Further research will help clarify whether or not there is a sex difference in rates of phone use while driving. Women are usually more risk averse than men (e.g., Croson \& Uri 2009; Kruger, Wang, \& Wilke, 2007), so perhaps greater aversion to the risks of distracted driving would counter-act women's greater tendencies for verbal communication compared to men (e.g., Tannen, 1990).

Drivers were less likely to use phones when it was raining. Hazardous driving conditions may increase concerns for the likelihood of accidents when attention is divided. The increased cognitive load of driving in wet conditions may interfere with the ability to operate phones and process conversations. Self-report survey research may help identify individual perceptions of the risk of driving in hazardous conditions and how this relates to cell phone use.

Drivers with passengers were less likely to be observed using their phones than those without passengers. There is a general consensus that using cell phones while in the company of others interferes with live conversations (Rainie \& Zickuhr, 2015). Young adults consider cell phone use during conversations with companions only moderately appropriate, and older adults see it as even less appropriate (Forgays et al., 2014). Relationships can be adversely affected by divided attention between one's partner and one's phone (e.g., Roberts \& David, 2016). Thus, drivers may be less likely to place outgoing and answer incoming calls when they have company in the vehicle.

\section{Limitations}

We may underrepresent the proportion of drivers using their phones, as observers may not always see active phone use. Underestimation is likely largest for the rate of Bluetooth calls. We assume that drivers with passengers who are observed to be talking without a phone in hand are talking with their passengers. It is possible that they are on a Bluetooth call. We also do not include drivers on a Bluetooth call who are listening rather than talking at the time of observation. Drivers of older vehicles may not have Bluetooth call capability; however, most cellphones have a speakerphone function that would also enable hands-free calls. It is possible that it was more difficult to observe cell phone use when it was raining, however observers reported that weather did not interfere with their determinations. Individuals classified as texting may have been performing other tasks such as dialing phone numbers or scrolling through social media, though the consequences for driving behaviors are likely to be similar.

\section{Conclusion}

This study documents a considerable prevalence of cell phone use while driving in a US collegetown population, increasing the risk of accidents to both these drivers and other drivers and pedestrians in the area. We demonstrate the value of observational studies for understanding technology use; our results complement those of self-report survey research on cell phone use. Naturalistic observations are valuable for investigating issues related to illegal and/or socially undesirable behaviors and may be superior to self-report survey results in their utility to inform policy-making. 


\section{REFERENCES}

Boase, J., \& Ling, R. (2013). Measuring mobile phone use: Self-report versus log data. Journal of Computer-Mediated Communication, 18, 508-519. DOI

Croson, R., \& Uri, G. (2009). Gender differences in preferences. Journal of Economic Literature, 47(2), 448-474. DOI

Demirci, K., Akgonul, M., \& Akpinar, A. (2015). Relationship of smartphone use severity with sleep quality, depression, and anxiety in university students. Journal of Behavioral Addictions, 4(2), 85-92. DOI

Dingus, T.A., Guo, F., Lee, S., Antin, J.F., Perez, M., Buchanan-King, M., \& Hankey, J. (2016). Driver crash risk factors and prevalence evaluation using naturalistic driving data. Proceedings of the National Academy of Sciences of the United States of America. Social Sciences, 113, (10), 2636-2641. DOI

Elhai, J. D., Dvorak, R. D., Levine, J. C., \& Hall, B. J. (2017). Problematic smartphone use: A conceptual overview and systematic review of relations with anxiety and depression psychopathology. Journal of Affective Disorders, 207, 251-259. DOI

Elhai, J. D., Tiamiyu, M. F., Weeks, J. W., Levine, J. C., Picard, K. J., \& Hall, B. J. (in press). Depression and emotion regulation predict objective smartphone use measured over one week. Personality and Individual Differences. DOI

Festinger, L., Riecken, H.W., \& Schachter, S. (1956). When prophecy fails. New York: Harper and Row.

Finkel, J.A. \& Kruger, D.J. (2012). Is cell phone use socially contagious? Human Ethology Bulletin, 27, 15-17.

Forgays, D. K., Hyman, I., \& Schreiber, J. (2014). Texting everywhere for everything: Gender and age differences in cell phone etiquette and use. Computers in Human Behavior, 31, 314-321. DOI

Geertz, C. (1973). Thick description: Toward an interpretive theory of culture. New York: Basic Books.

Hallet, C., Lambert, A., \& Regan, M.A. (2011). Cell phone conversing while driving in New Zealand: Prevalence, risk perception and legislation. Accident Analysis and Prevention, 43, 862-869. DOI

Jeong, S.-H., Kim, H., Yum, J.-Y., \& Hwang, Y. (2016). What type of content are smartphone users addicted to?: SNS vs. games. Computers in Human Behavior, 54, 10-17. DOI

Kruger, D.J., Duan, A., Juhasz, D., Phaneuf, C.V., Sreenivasa, V., Saunders, C., Heyblom, A., Sonnega, P., Day, M.M., \& Misevich, S.L. (2017). Cell phone use latency in a university area population in the Midwestern USA. Journal of Technology in Behavioral Science, 2(1), 56-59. DOI

Kruger, D.J., \& Djerf, J.M. (2015). High ringxiety: Attachment anxiety predicts experiences of phantom cell phone ringing. Cyberpsychology, Behavior, and Social Networking, 19, 1-4. $\underline{\mathrm{DOI}}$

Kruger, D.J., \& Djerf, J.M. (2017). Bad vibrations? Cell phone dependency predicts phantom communication experiences. Computers in Human Behavior, 70, 360-364. DOI

Kruger, D.J., Wang, X. T., \& Wilke, A. (2007). Towards the development of an evolutionarily valid domain-specific risk-taking scale. Evolutionary Psychology, 5, 570-583. DOI

Lepp, A., Li, J., Barkley, J., \& Salehi-Esfahani, S. (2015). Exploring the relationships between college students' cell phone use, personality and leisure. Computers in Human Behavior, 43, 210-219. DOI

Lipovac, K., Đeric', M., TeŠic', M., Andric', Z., \& Maric', B. (2017). Mobile phone use while driving-literary review. Transportation Research Part F, 47, 132-142. DOI 
McEvoy, S. P., Stevenson, M. R., McCartt, A. T., Woodward, M., Haworth, C., Palamara, P., \& Cercarelli, R. (2005). Role of mobile phones in motor vehicle crashes resulting in hospital attendance: A case-crossover study. British Medical Journal, 331, 428-433. DOI

Pew Research Center. (2015, April 01). The Smartphone Difference: US smartphone use in 2015. Available at: http://www.pewinternet.org/2015/04/01/us-smartphone-use-in-2015/

Pew Research Center. (2017, June 28). 10 facts about smartphones as the iPhone turns 10. Retrieved from http://www.pewresearch.org/fact-tank/2017/06/28/10-facts-aboutsmartphones/

Rainie, \& Zickuhr (2015). Americans views on mobile etiquette. Pew Research Center. Retrieved from http://www.pewinternet.org/2015/08/26/americans-views-on-mobile-etiquette/

Roberts, J. A., \& David, M. E. (2016). My life has become a major distraction from my cell phone: Partner phubbing and relationship satisfaction among romantic partners. Computers in Human Behavior, 541, 34-141. DOI

Roberts, J. A., Yaya, L. H., \& Manolis, C. (2014). The invisible addiction: Cell-phone activities and addiction among male and female college students. Journal of Behavioral Addictions, 3, 254-265. DOI

Rosen, L. D., Cheever, N. A., \& Carrier, L. M. (2012). iDisorder: Understanding our obsession with technology and overcoming its hold on us. New York: Palgrave-MacMillian.

Sanbonmatsu, D.M., Strayer, D.L., Biondi, F., Behrends, A.A., \& Moore, S.M. (2016). Cell-phone use diminishes self-awareness of impaired driving. Psychonomic Bulletin \& Review, 23, 2, 617-623. DOI

Strayer, D.L., Cooper, J.M., Turrill, J., Coleman, J., Nate Medeiros-Ward, N., \& Francesco Biondi, F. (2013). Measuring Cognitive Distraction in the Automobile. Washington, DC: AAA Foundation for Traffic Safety.

Strayer, D. L., Drews, F. A., \& Crouch, D. J. (2006). A comparison of the cell phone driver and the drunk driver. Human Factors, 48, 381- 391. DOI

Tannen, D. (1990). You Just Don't Understand: Women and Men in Conversation. New York: Ballantine.

Terry, C.P. \& Terry, D.L. (2016). Distracted driving among college students: Perceived risk versus reality. Current Psychology, 35(1), 115-120. DOI

van Deursen, A.J.A.M., Bolle, C.L., Hegner, S.M., \& Kommers, P.A.M. (2015). Modeling habitual and addictive smartphone behavior: Modeling habitual and addictive smartphone behavior: The role of smartphone usage types, emotional intelligence, social stress, self-regulation, age, and gender. Computers in Human Behavior, 45, 411-420. $\underline{\mathrm{DOI}}$

van Kleef, E., van Trijpa, H.C.M., \& Luning, P. (2005). Consumer research in the early stages of new product development: a critical review of methods and techniques. Food Quality and Preference, 16, 181-201. DOI

Violanti, J. M. (1999). Cellular phones and fatal traffic collisions. Accident Analysis and Prevention, 30(4), 519-524. DOI

Wang, J.-L., Wang, H.-Z., Gaskin, J., \& Wang, L.-H. (2015). The role of stress and motivation in problematic smartphone use among college students. Computers in Human Behavior, 53, 181-188. DOI 